\title{
Changes in family composition and their effects on social capital in old age: evidence from a longitudinal study conducted in Switzerland
}

\author{
Julia Sauter ${ }^{1,2 *}$ (D), Eric Widmer ${ }^{2,3}$ and Matthias Kliegel ${ }^{1,2,4}$ \\ ${ }^{1}$ Center for the Interdisciplinary Study of Gerontology and Vulnerability, University of Geneva, Geneva, \\ Switzerland, ${ }^{2}$ Swiss National Centre of Competence in Research LIVES - Overcoming Vulnerability: Life \\ Course Perspectives, Lausanne and Geneva, Switzerland, ${ }^{3}$ Department of Sociology, University of Geneva, \\ Geneva, Switzerland and ${ }^{4}$ Department of Psychology, University of Geneva, Geneva, Switzerland \\ ${ }^{*}$ Corresponding author. Email: Julia.Sauter@unige.ch
}

(Accepted 14 May 2021; first published online 8 July 2021)

\begin{abstract}
Previous studies have shown that family networks evolve over time. Nonetheless, little research has linked family expansion or shrinking to the levels of available family-based social capital in older adults' family networks. To address this research gap, this paper explores the following question: to what extent are changes in family composition and family-related life events associated with current levels of family-based social capital in later years? We use the two waves of the longitudinal CIGEV-LIVES Vivre-LebenVivere study, a large survey addressing the family and health conditions of older people in Switzerland. We combine data on life events occurring during old age and family configurations. We find that family networks are indeed highly dynamic, with distinct patterns of losses and gains observed among respondents. Adding and omitting significant family members has distinct significant effects on social capital, while family-related life events only have marginal effects.
\end{abstract}

Keywords: old age; family; social capital; family composition

\section{Introduction}

During the final stages of life, family becomes an increasingly important source of family-based social capital in older adults' lives (Field and Minkler, 1988). Meaningful family ties indeed serve as major sources of relational resources and therefore represent a key factor of wellbeing and self-identity in later life (Antonucci, 2001; Thoits, 2011). Support provided by family members, including informational, instrumental and emotional support, has a protective effect against decline in physical and mental health, as it quells feelings of isolation (Coll-Planas et al., 2017). Individuals who lack meaningful and positive family ties are more 
likely to experience depression, lower levels of self-rated health and subjective wellbeing, as well as higher risks of disease and mortality, as they lack efficient coping mechanisms and emotional self-regulation (Pinquart and Sörensen, 2000; Shor et al., 2013). Until now, most research has focused on the importance of the compositional stability of those family ties for maintaining high levels of family-based social capital, and evidence of the effect of adding or removing ties to or from the family network on family-based social capital in old age is not yet conclusive (van Tilburg, 1998; van Tilburg and Groenou, 2002).

\section{Theoretical background}

Family-based social capital are resources produced within a sustainable network of family relationships and to which the individual - as a member of the network - has access when needed (Cornwell et al., 2008; Widmer, 2010; Cornwell and Schafer, 2016). Whatever their nature, these resources are exchanged between the focal individual and the members of her or his family, and it is these multiple transfers, regulated by rules of exchange (e.g. reciprocity), which produce family-based social capital over time (Portes, 1998, 2000). This is indeed a long process during which exchanges, based on reciprocity and fuelled by the personal investments of network members (support, time, etc.), transform casual, non-meaningful relationships into emotionally engaged, interdependent bonds supported by mutual recognition and feelings of obligation (Portes, 1998; Kadushin, 2012). This construction of family-based social capital involves a time-dependent process facilitated through multiple exchanges and recognition, and it feeds on a sense of obligation linked to the family realm. Family-based social capital is accumulated through personal interactions with specific alters over time and is expected to change as life events unfold and personal resources vary (van Tilburg, 1998; van Tilburg and Groenou, 2002; Aartsen et al., 2004).

To account for the protective role of family ties over the lifecourse, Antonucci et al. (1990, 2010, 2014) sketched the 'Convoy Model of Social Relations', which postulates that the focal individual is, throughout her life, accompanied by people who provide her with the resources and support that she needs to develop socially and to face the difficulties that punctuate her lifecourse. This group of people offers a protective environment that allows the individual to overcome adverse events and to preserve her health and wellbeing until the last stages of her life. In the Convoy Model, the closest circle (usually the partner and children) forms the core of the personal network and serves as the main source of social support in old age. The members of the nuclear family, either by orientation or procreation (Parsons, 1955), are defined as 'significant' others to whom the individual is strongly attached. These relationships are described as reliable and rather stable over time regardless of lifecourse events that the individual is likely to have encountered (Antonucci et al., 2014).

The extent to which personal and family networks of older adults remain stable over time has, however, received some attention from empirical studies. For instance, van Tilburg (1998) found the size of older adults' networks to stay stable over a four-year longitudinal study and found the number of close relatives within the networks to increase. However, although network sizes stayed stable, widely 
varying patterns of gains and losses within the networks were observed. Similar results were found in another study by van Tilburg and Groenou (2002), who investigated the relationship between network and health changes. Using longitudinal data for a period of seven years, they found that on average, network sizes remained roughly the same, but large individual variations were observed. Approximately equal proportions of individuals from the referenced sample experienced either an increase or decrease in their network sizes. Wrzus et al. (2013) conducted a meta-analysis on social network changes occurring across the lifespan. They found that cross-sectional and longitudinal studies consistently show that while friendship networks decrease in size throughout adulthood, the size of family networks remains stable from adolescence to old age. Concerning potential reasons of these changing network dynamics, Cornwell (2015) found social disadvantages and poorer health to be associated with higher rates of network turnover in old age. Another reason for such dynamics of change and turnover may lie in the so-called 'kinship reservoir' (Widmer, 2010; De Carlo et al., 2014). The kinship reservoir refers to a pool of relatives present in the focal individual's life, whether they are significant family members of the focal individual or not. The kinship reservoir can be conceptualised as a demographic family reserve composed by family members from different generations (Cullati et al., 2018). The family ties that constitute this reserve can be activated, reactivated or deactivated over the lifecourse, depending on the current needs of the focal individual. Indeed, currently activated significant family ties form part of the kinship reservoir and can be replaced by other ties in the future.

\section{Present study}

Although theoretical and empirical arguments postulate that compositional stability and change are of great importance when studying family and personal networks of older adults over time, little empirical research has actually measured the extent of such change and addressed their potential impacts on family-based social capital. This study addresses this gap and investigates to what extent compositional stability within family networks and change increase or decrease levels of available family-based social capital, i.e. emotional support stemming from the family network. We thus anticipate that family networks that stayed stable in their composition between survey waves provide higher levels of social capital to their focal individuals compared to those networks that were more instable (in terms of removed and added family members) (Hypothesis 1). A small family network that remains stable in its composition over time can be associated with higher levels of social capital, because the way in which network members are connected with each other can change over time. For instance, one could imagine a network including one daughter and the daughter's partner. In the first wave, the focal individual might only be connected to the daughter's partner through her daughter, however in the second wave, there can be a direct and reciprocal connection between the daughter's partner and the focal individual, leading to a higher level of available social capital.

In addition, critical life events happening in later stages of life may be crucial to an increase or decrease in available family-based social capital. As individuals age, 
life events are likely to affect their family configurations in a way that permanently changes their available family-based social capital. For instance, the death of a partner or of other significant family members in old age can be expected, but it is often experienced as traumatic. Various losses (of partners, siblings and other family members) experienced in old age can lead to smaller family networks, especially if new alters (stemming from the kinship reserve) are not mobilised. We therefore hypothesise that experiencing such critical family-related life events predicts lower levels of available family-based social capital (Hypothesis 2).

In summary, family-based social capital may change as much in old age as it does in other lifestages (Adams, 1987; Wrzus et al., 2013). We hypothesise that stability and changes in alters within the family network play a critical role in the availability of family-based social capital. We argue that family ties are dynamic and that family networks change over time either as a result of disruptive effects of life events or by choice, e.g. as a consequence of family conflict (van Tilburg, 1998; Lüscher, 2002; Lubbers et al., 2010). However, until now, most researchers have used aggregate measures such as network size or network complexity to calculate whether stability or changes occur within such networks (van Tilburg, 1998). Therefore, the aim of this study is to investigate to what extent compositional stability and change in family configurations as well as family-related life events impact older adults' available family-based social capital using detailed unaggregated measures of social capital from a sample of retired individuals living in Switzerland.

\section{Methods}

\section{Participants}

Data come from the two waves of the Vivre-Leben-Vivere survey (Ludwig et al., 2014; Ihle et al., 2017, 2018; Sauter et al., 2018) developed as part of the LIVES research programme on vulnerability processes occurring across the lifecourse. Respondents were first interviewed in 2011 (Wave 1 (W1)) using a face-to-face computer-assisted personal interview method and questionnaires. The main sample used for W1 included 3,080 participants who were randomly selected from cantonal Swiss administration records and stratified by age (65-69, 70-74, 75-79, 80-84, 85$89,90+$ ), sex and canton (Basel, Bern, Geneva, Ticino, Valais). A sub-sample of 1,059 participants from four cantons (Basel, Bern, Geneva, Valais) were interviewed again in 2017 (Wave 2 (W2)). From those initial 3,080 participants, 606 were living in the canton of Ticino and were not included in W2. Moreover, 451 individuals could not be traced and contacted again, while 463 participants refused to be interviewed again. Finally, 501 individuals died between survey waves, leading to 1,059 participants in W2.

Concerning some key socio-demographic variables, it should be noted that in W1 the sample's mean age was 78.33 years, while it was 80.9 years for the analytical sample of this study. In both waves, men are slightly more represented than women (51.7\% in W1 and 51.3\% in W2). With regards to education, in W1 a large majority of participants (71.2\%) had secondary education as the highest level of education, while 28.8 per cent had a university degree. Meanwhile, the sample in W2 was 
composed of 45 per cent of participants who had secondary education as the highest level of education and 55 per cent had a university degree. This indicates that more-educated participants took part in the second survey wave more frequently than less-educated participants.

Due to the interview lengths, the family network questionnaire was randomly assessed for two-thirds of the main sample in W2, leading to a sub-sample of 671 participants who completed the family network questionnaire in W1 and W2. This sub-sample was used for our data analysis.

\section{Indicators of family-based social capital}

Applying standard procedures for collecting information on family networks (Widmer et al., 2013), respondents were asked to name their five most significant family members. There has been a growing emphasis in European family research on family configurations that serve as alternatives to the nuclear family defined by marriage and household membership (e.g. Budgeon and Roseneil, 2004). Such research starts empirical analyses from the point of view that what makes family is the inclusion of individuals in a 'we' or 'weness', that is a co-constructed feeling of being part of a family (Elias and Scotson, 1994; Castrén and Widmer, 2015; Castrén, 2019). To understand how identification to a family group unfolds, a series of configurational studies ask focal individuals to report their significant family members (Widmer et al., 2013; Zartler, 2014; Castrén and Ketokivi, 2015). To keep responses as broad as possible, each participant was asked to use his or her own definition of who constitutes a member of their family (Girardin and Widmer, 2015). Participants were told that the term significant refers to people in their family who have played an either positive or negative role over the past year. This open question allowed us to capture supportive but also ambivalent relationships that occur within family networks.

Participants were then asked a set of questions about support received from the listed family members. To approach family-based social capital, we focus on available emotional support among family members as perceived by the respondents. Emotional support is defined as the ability to receive guidance and moral comfort whenever needed (Girardin and Widmer, 2015). It was measured with the following question: 'Who would provide emotional support to $\mathrm{X}$ [i.e. each individual included in the respondent's family configuration and considered one by one] when routine or minor troubles are experienced?' The respondents were required to evaluate not only their own supportive ties but also those among all of the significant family members they had listed (Widmer et al., 2013). Based on the responses provided, network indexes suitable for assessing the properties of egocentric networks in relation to the structural characteristics of family-based social capital were computed for all of the respondents' family networks (Scott, 2007; Perry, 2018). These indexes are detailed in the following paragraph and were used as the outcome variables of this study.

Density denotes how closely connected family members are to one another. It is a dimension of social capital that was shown to be of major importance in other lifestages and transitions (Moren-Cross and Lin, 2006). It refers to the proportion of supportive ties (namely a tie indicates a relationship of support existing between 
two people) over the number of the total possible ties existing in a family network according to the number of persons present. For instance, a family network composed of six people (the focal individual and five significant family members) includes 30 potential supportive relationships $(5 \times 6=30)$. If only 15 of those relationships are described as supportive by the respondent, the density of the network is going to be 50 per cent. Density indicates the degree of tightness of interconnections among members of family networks (Scott, 2007). A dense network is one where all, or almost all, network members are interconnected, whereas a non-dense network features only a few ties among network members. The indicator is valued on a scale from 0 to 1 where a value of 1 means that there are as many existing ties as possible within the family network (Broese van Groenou and van Tilburg, 2007).

Reciprocity measures the extent to which support is exchanged in reciprocal connections among all family members. It is calculated as the ratio of reciprocal ties in the number of connected dyads within family networks. Reciprocity is measured on a scale of 0 to 1 , where a value of 0 means that no tie is reciprocal and with a value of 1 meaning that all family ties are reciprocal (Moren-Cross and Lin, 2006; Broese van Groenou and van Tilburg, 2007).

In-degree centrality measures the extent to which the focal individual provides emotional support to other family members. This index ranges from 0 to 5 , with a value of 5 indicating that the respondent supports all significant family members. Each respondent's out-degree centrality value indicates how much emotional support the focal individual receives from family network members. In the social network literature, in-degree centrality typically refers to the number of receiving ties and out-degree centrality to the number of ties one is sending out (Scott, 2007). However, in the Vivre-Leben-Vivere survey, we assessed family networks by asking respondents 'Who would give emotional support to $\mathrm{X}$ during minor problems?' By asking the question in this particular way, the incoming ties (in-degree centrality) represent the support that the focal individual gives to family members, while the ties sent out (out-degree centrality) represent the support the focal individual receives from family members (Girardin and Widmer, 2015).

Each respondent's betweenness centrality value measures the extent to which network members serve as intermediaries between their significant family members. Each respondent's betweenness centrality value was computed as the ratio of the shortest paths between any two family members going through the focal individual (Marsden, 2002; Everett and Borgatti, 2005). Focal individuals are considered central if they were lying between all, or almost all, of their family members' connections. Lying between alters in one's family network increases older adults' independence and autonomy but it can also be a hindrance in the access to a collective kind of support, as network members are typically less connected with each other (Widmer, 2006). This index varies from 0 to 1 with a value of 1 indicating that all family members went through the respondent to reach one another.

\section{Family compositional stability and change}

Having interviewed participants about their family networks at two points in time (2011 and 2017), we were able to compute an indicator of compositional stability and change, allowing us to determine how many people had stayed in their 
networks, how many left over time and how many had been added between the two survey waves. To do so, for each participant we compared family terms (such as 'partner', 'daughter', 'daughter's partner', etc.), identifying family network members from W1 with those mentioned in W2. To ensure that compositional stability was not correlated with network size in W1, we divided the number of family members mentioned in both waves by the network size given in W1. This approach allowed us to avoid including participants with a smaller network size in W1, who would have automatically exhibited less compositional stability, i.e. when a participant mentioned one alter in W1 and the same alter in W2, their compositional stability was calculated as 1 (Feld et al., 2007; Lubbers et al., 2010; Cornwell, 2015).

Compositional stability was rated from 0 to 1 with a value of 0 meaning that no family member mentioned in W1 was mentioned again in W2 and with a value of 1 meaning that all family members mentioned in W1 were mentioned again in W2. The measure of compositional stability is not an indicator that informs us about the structure of the family configuration. It is rather a measure of the family inclusiveness of focal individuals in both waves (Castrén and Widmer, 2015). This measurement indeed refers to the extent to which the inclusion of specific alters in the family definition of the focal individual goes beyond the definition of family as nuclear, i.e. focusing on partner and children. Such inclusions proved to be significant for a number of issues related with the lifecourse, such as the choice of the family name (Castrén, 2019), the family organisation after divorce (Zartler, 2014) or the way by which conflict is dealt with in later-year families (Girardin et al., 2018). Additionally, we computed the number of new alters given in W2 and the number of alters from W1 who had been removed by W2. Including this measure enabled us to collect additional information on the importance of new ties relative to stable ties and on the impact of ties that cease to exist. We acknowledge that these three variables (compositional stability, added alters, removed alters) are correlated. However, the variance inflation factors are all below 5 , indicating that there is no issue with regards to multicollinearity (Sheather, 2009).

\section{Family-related critical life events}

To assess whether the participants had experienced critical life events since the first survey wave, they were asked about a series of life events that may have happened between the two waves in various life domains, including family, residence and health. To account for potential effects on non-normative life events, we were interested in family and health-related life events. Family-related life events included the death of a partner and the death of other family members. One should note that these family deaths can also include family members not cited in the participant's family network.

\section{Control variables}

As it is strongly correlated with other family-based social capital indicators, such as density and reciprocity (Girardin and Widmer, 2015), we controlled for network size in W1 with values varying from 0 to 5 . Processes of loss and gain observed in personal networks are at least partly determined by the number and types of 
health problems experienced in old age (Broese van Groenou et al., 2013). To account for the impact of health status on family-based social capital, we took into consideration three critical life events related to health as control variables. Participants were asked if they had experienced a fall between W1 and W2, if they have had experienced an accident other than a fall between W1 and W2, and if the had stayed in hospital for more than a week since W1. We also used subjective health as a control. Subjective health was measured in W1 by asking the participants how they evaluate their current health status. The scale for this indicator ranged from 0 (very poor subjective health) to 100 (excellent subjective health) (EuroQoL Group, 1990). We also considered each participant's gender $(1=$ female; $2=$ male), age in W2 and level of education $(0=\mathrm{low} / \mathrm{mid}-$ up to high school or equivalent); 1 = high - university or equivalent) as control variables in our statistical model.

\section{Statistical analysis}

To determine how the composition of family networks (translating respondents' personal definitions of family) varied across the survey waves, we identified the most cited significant family terms. Overall, respondents provided 2,477 citations of family members using 91 family terms in W1 and 2,490 using 77 family terms in W2. We then calculated the means and standard deviation (SD) of all family-based social capital indicators for W1 and W2 to compare them over time. We also computed means and SD as well as the distributions for compositional stability and change. To assess family-based social capital according to family networks' levels of compositional stability and changes, family-related critical life events and control variables, we ran multiple linear regression models with family-based social capital measures adopted in W2 used as dependent variables.

\section{Results}

\section{Compositional stability and change in family networks}

Mean compositional stability was recorded as $0.6(\mathrm{SD}=0.32)$, which means that, on average, focal individuals had kept roughly two-thirds of their family members from W1 in W2. Over 25 per cent of the focal individuals maintained fully identical family network compositions between W1 and W2. Simultaneously, over 10 per cent of the focal individuals' family network compositions had completely changed between the two survey waves, meaning that no alter cited in W1 was cited again in W2. In total, 70 per cent of the focal individuals added one or more new alters to their networks and 69 per cent omitted one or more alters between the survey waves. Focal individuals, on average, added $1.5(\mathrm{SD}=1.4)$ new ties to their networks and removed $1.47(\mathrm{SD}=1.3)$ old ties between $\mathrm{W} 1$ and W2. Given that the survey's name generator was limited to five family members, these proportions indicate a rather high level of turnover amongst older adults' family members.

Regarding the frequency of cited family members, Table 1 displays the frequencies and percentages of the six most cited family terms. Brothers and sisters were cited less in W2 than in W1, and children and grandchildren were cited more in 
Table 1. Distributions of family terms most frequently cited in Waves 1 and 2 (W1 and W2)

\begin{tabular}{|c|c|c|c|c|c|c|}
\hline $\begin{array}{l}\text { Family } \\
\text { terms }\end{array}$ & $\begin{array}{c}\mathrm{N} \\
(\mathrm{W} 1)\end{array}$ & $\begin{array}{c}\text { Percentage of all cited family } \\
\text { terms (W1) }\end{array}$ & $\begin{array}{l}\text { Percentage of } \\
\text { participants }\end{array}$ & $\begin{array}{c}N \\
(W 2)\end{array}$ & $\begin{array}{l}\text { Percentage of all cited family } \\
\text { terms (W2) }\end{array}$ & $\begin{array}{l}\text { Percentage of } \\
\text { participants }\end{array}$ \\
\hline Daughter & 505 & 23.5 & 75.1 & 536 & 24.5 & 79.7 \\
\hline Son & 504 & 23.5 & 75.0 & 551 & 25.1 & 81.9 \\
\hline Partner & 380 & 17.7 & 56.5 & 373 & 17.0 & 55.5 \\
\hline Grandchild & 199 & 9.3 & 29.6 & 255 & 11.6 & 37.9 \\
\hline Sister & 177 & 8.2 & 26.3 & 144 & 6.6 & 21.4 \\
\hline Brother & 114 & 5.3 & 16.9 & 96 & 4.4 & 14.3 \\
\hline
\end{tabular}


W2 than in W1. Partners were cited almost equally as often in W2 as in W1, even though 8 per cent of our sample experienced the death of their partner between the survey waves. Overall, sons and daughters accounted for 50 per cent of all of the cited family terms.

\section{Social capital measures}

Table 2 shows how indicators of family-based social capital changed between W1 and W2, and Table 3 shows the paired samples $t$-test evaluating whether changes observed between the survey waves were significant. Network sizes remained largely stable between $\mathrm{W} 1$ and $\mathrm{W} 2$, changing from $3.68(\mathrm{SD}=1.41)$ in $\mathrm{W} 1$ to 3.73 (SD = $1.29)$ in $\mathrm{W} 2$. Overall, 40.2 per cent $(\mathrm{N}=270)$ of respondents mentioned five family members, while 0.7 per cent $(\mathrm{N}=5)$ reported having no significant family members. Average network density levels significantly decreased from $0.41(\mathrm{SD}=0.27)$ to $0.33(\mathrm{SD}=0.22)$ from $\mathrm{W} 1$ to $\mathrm{W} 2$. Mean reciprocity levels between family network members significantly decreased from $0.47(\mathrm{SD}=0.33)$ to $0.24(\mathrm{SD}=0.25)$ from $\mathrm{W} 1$ to $\mathrm{W} 2$. In-degree centrality (support given from the focal individual to alters) also significantly declined from $2.33(\mathrm{SD}=1.50)$ to $1.54(\mathrm{SD}=1.29)$ from $\mathrm{W} 1$ to W2. Out-degree centrality (support that the focal individual received from alters) significantly increased from $1.56(\mathrm{SD}=1.26)$ to $1.77(\mathrm{SD}=1.37)$ from $\mathrm{W} 1$ to $\mathrm{W} 2$. Betweenness centrality remained stable from $0.14(\mathrm{SD}=0.22)$ to 0.16 $(\mathrm{SD}=0.19)$ from $\mathrm{W} 1$ to $\mathrm{W} 2$. It should be noted that the distribution of betweenness centrality in W2 is highly skewed (1.39).

\section{Regression analysis}

Table 4 displays a set of multivariate linear regressions that estimate the effects of compositional stability and new and omitted alters for $\mathrm{W} 2$ relative to $\mathrm{W} 1$ and of family-related life events occurring between W1 and W2 on social capital measures. Meanwhile, we controlled for the effects of health-related life events occurring between W1 and W2, self-rated health levels reported in W1, gender, age and levels of education. It should be noted that density and reciprocity are two measures that describe the entire family network (ties between all family members), while in-degree, out-degree and betweeness centrality are measures that reflect the focal individual's position in the network.

Density among family members in W2 was found to be negatively associated with the addition of new alters in W2 $(\beta=-0.12, p<0.05)$. Neither compositional stability nor omitted alters between survey waves were found to be associated with density levels measured in W2. Reciprocity measured in W2 was found to be positively associated with adding new alters in W2 $(\beta=0.20, p<0.01)$. In terms of life events, reciprocity was found to be positively associated with the death of a partner since W1 $(\beta=0.11, p<0.05)$ and was recorded as negatively associated with the death of a family member, other than the partner $(\beta=-0.10, p<0.05)$. In-degree centrality, meaning the number of family members supported by a respondent (support that the focal individual gives to family members) in W2 was found to be positively associated with adding new alters in W2 $(\beta=0.49, p<0.001)$ and to be negatively associated with the number of omitted alters in W2 $(\beta=-0.49$, 
Table 2. Family-based social capital measures used in Waves 1 and 2 (W1 and W2)

\begin{tabular}{|c|c|c|c|c|c|c|}
\hline Variable & \multicolumn{2}{|c|}{ Mean (SD) } & \multicolumn{2}{|c|}{ Skewness } & $\begin{array}{c}\text { Minimum } \\
\text { W2 }\end{array}$ & $\begin{array}{c}\text { Maximum } \\
\text { W2 }\end{array}$ \\
\hline \multicolumn{7}{|l|}{ Network level: } \\
\hline Network size & $3.68(1.41)$ & $3.73(1.29)$ & -0.89 & -0.67 & 0 & 5 \\
\hline Density & $0.41(0.27)$ & $0.33(0.22)$ & 0.77 & 0.68 & 0.00 & 0.83 \\
\hline Reciprocity & $0.47(0.33)$ & $0.24(0.25)$ & 0.24 & 0.79 & 0.00 & 1.00 \\
\hline In-degree centrality & $2.33(1.50)$ & $1.54(1.29)$ & 0.24 & 0.45 & 0.00 & 4.00 \\
\hline Out-degree centrality & $1.56(1.26)$ & $1.77(1.37)$ & 1.09 & 0.96 & 0.00 & 5.00 \\
\hline Betweenness centrality & $0.14(0.22)$ & $0.16(0.19)$ & 1.93 & 1.39 & 0.00 & 0.95 \\
\hline
\end{tabular}

Note: SD: standard deviation. 
Table 3. Paired samples $t$-test of family-based social capital indicators

\begin{tabular}{lrrcc}
\hline & $t$ & $\mathrm{df}$ & Significance (two-tailed) \\
\hline Pair 1: Network size (W1 and W2) & 0.63 & 670 & 0.528 \\
\hline Pair 2: Density (W1 and W2) & -6.37 & 670 & 0.000 \\
\hline Pair 3: Reciprocity (W1 and W2) & -14.83 & 670 & 0.000 \\
\hline Pair 4: In-degree centrality (W1 and W2) & -11.65 & 670 & 0.000 \\
\hline Pair 5: Out-degree centrality (W1 and W2) & 3.24 & 670 & 0.001 \\
\hline Pair 6: Betweenness centrality (W1 and W2) & 1.20 & 670 & 0.231 \\
\hline
\end{tabular}

Notes: W1: Wave 1. W2: Wave 2. df: degrees of freedom.

$p<0.001)$. Moreover, it was found to be associated with the number of family members supported by the respondent (in-degree centrality) in W1 $(\beta=0.11$, $p<0.05)$ and by respondent's network size in W1 $(\beta=0.59, p<0.001)$. Concerning the effects of health-related events, the number of family members supported by the focal individual was found to be positively associated with experiencing an accident since W1 $(\beta=0.08, p<0.05)$. Out-degree centrality, meaning the number of family members supporting respondents (support that the focal individual receives from family members) was recorded as positively predicted by new alters $(\beta=0.33, p<0.001)$ and negatively predicted by omitted alters $(\beta=-0.30, p<0.001)$ in W2. The number of family members supporting respondents (out-degree centrality) was also found to be negatively predicted by self-rated health status in W1 $(\beta=-0.12, p<0.01)$. The number of family members supporting the focal individual in W1 $(\beta=0.16, p<0.001)$ and network size in W1 $(\beta=0.38, p<0.001)$ both positively predicted the number of family members supporting the respondent in W2. The focal individual's level of betweenness centrality among family members was found to be negatively predicted by the number of new alters in W2 $(\beta=-0.14, p<0.01)$. It is worth noting that compositional stability predicted none of the family-based social capital measures. Overall, the findings refute Hypothesis 1 and indicate that changes in family compositions rather than their stability have a significant effect on levels of social capital. Moreover, the findings refute Hypothesis 2 and indicate that family-related life events have only marginal effects on available family-based social capital.

For the control variables, the results show that participants with higher levels of education were less central in their networks. Education had no significant association with any of the other family-based social capital measures $(\beta=-0.11$, $p<0.05)$. Age was found to be negatively correlated with betweenness centrality in W2 $(\beta=-0.16, p<0.01)$ but to have no significant effect on any other familybased social capital measures. Concerning gender effects, men were found to provide support to fewer family members than women $(\beta=-0.11, p<0.05)$.

\section{Discussion}

The purpose of the present study was to investigate the impact of compositional stability and changes on available social capital within family networks in old 


\begin{tabular}{|c|c|c|c|c|c|c|c|c|c|c|}
\hline & \multicolumn{2}{|c|}{ Density (W2) } & \multicolumn{2}{|c|}{ Reciprocity (W2) } & \multicolumn{2}{|c|}{$\begin{array}{l}\text { In-degree centrality } \\
\text { (W2) }\end{array}$} & \multicolumn{2}{|c|}{$\begin{array}{l}\text { Out-degree } \\
\text { centrality (W2) }\end{array}$} & \multicolumn{2}{|c|}{$\begin{array}{l}\text { Betweenness } \\
\text { centrality (W2) }\end{array}$} \\
\hline & $\beta$ & SE & $\beta$ & SE & $\beta$ & SE & $\beta$ & SE & $\beta$ & SE \\
\hline Compositional stability & $0.02 \mathrm{~ns}$ & 0.06 & $0.05 \mathrm{~ns}$ & 0.08 & $-0.03 \mathrm{~ns}$ & 0.32 & $0.07 \mathrm{~ns}$ & 0.37 & $-0.06 \mathrm{~ns}$ & 0.06 \\
\hline New alters in $W 2$ & $-0.12^{\star}$ & 0.01 & $0.20^{\star \star}$ & 0.01 & $0.49^{\star \star \star}$ & 0.04 & $0.33^{\star \star \star}$ & 0.05 & $-0.14^{\star}$ & 0.01 \\
\hline Omitted alters in W2 & $0.03 \mathrm{~ns}$ & 0.02 & $-0.08 \mathrm{~ns}$ & 0.02 & $-0.49^{\star \star \star}$ & 0.09 & $-0.30^{\star *}$ & 0.12 & $0.09 \mathrm{~ns}$ & 0.02 \\
\hline Death of a partner since $\mathrm{W} 1$ & $-0.01 \mathrm{~ns}$ & 0.04 & $0.11^{\star}$ & 0.04 & $-0.003 \mathrm{~ns}$ & 0.19 & $0.06 \mathrm{~ns}$ & 0.22 & $0.05 \mathrm{~ns}$ & 0.03 \\
\hline $\begin{array}{l}\text { Death of a family member since } \\
\text { W1 }\end{array}$ & $-0.03 \mathrm{~ns}$ & 0.02 & $-0.10^{\star}$ & 0.03 & $-0.01 \mathrm{~ns}$ & 0.12 & $-0.02 \mathrm{~ns}$ & 0.14 & $0.06 \mathrm{~ns}$ & 0.02 \\
\hline Partner in W1 & $0.09 \mathrm{~ns}$ & 0.03 & $0.03 \mathrm{~ns}$ & 0.03 & $0.06 \mathrm{~ns}$ & 0.13 & $0.01 \mathrm{~ns}$ & 0.27 & $0.01 \mathrm{~ns}$ & 0.02 \\
\hline Fall since W1 & $-0.07 \mathrm{~ns}$ & 0.04 & $-0.04 \mathrm{~ns}$ & 0.03 & $-0.03 \mathrm{~ns}$ & 0.12 & $-0.02 \mathrm{~ns}$ & 0.14 & $0.02 \mathrm{~ns}$ & 0.02 \\
\hline Accident since W1 & $0.02 \mathrm{~ns}$ & 0.05 & $0.01 \mathrm{~ns}$ & 0.05 & $0.08^{\star}$ & 0.23 & $0.01 \mathrm{~ns}$ & 0.27 & $0.06 \mathrm{~ns}$ & 0.04 \\
\hline Hospitalisation since W1 & $-0.06 \mathrm{~ns}$ & 0.02 & $-0.05 \mathrm{~ns}$ & 0.03 & $-0.002 \mathrm{~ns}$ & 0.12 & $-0.04 \mathrm{~ns}$ & 0.14 & $-0.04 \mathrm{~ns}$ & 0.02 \\
\hline Subjective health in W1 & $-0.06 \mathrm{~ns}$ & 0.001 & $-0.03 n s$ & 0.001 & $0.05 \mathrm{~ns}$ & 0.003 & $-0.12^{\star \star}$ & 0.003 & $-0.04 \mathrm{~ns}$ & 0.001 \\
\hline $\begin{array}{l}\text { Respective social capital } \\
\text { indicator in } \mathrm{W} 1\end{array}$ & $0.08 \mathrm{~ns}$ & 0.04 & $0.05 \mathrm{~ns}$ & 0.04 & $0.11^{\star}$ & 0.04 & $0.16^{\star \star \star}$ & 0.05 & $0.08 \mathrm{~ns}$ & 0.04 \\
\hline Network size in W1 & $0.05 \mathrm{~ns}$ & 0.01 & $0.28^{\star \star}$ & 0.02 & $0.59^{\star \star \star}$ & 0.07 & $0.38^{\star \star \star}$ & 0.08 & $0.01 \mathrm{~ns}$ & 0.01 \\
\hline Age in W2 & $0.01 \mathrm{~ns}$ & 0.002 & $-0.07 \mathrm{~ns}$ & 0.002 & $-0.08 \mathrm{~ns}$ & 0.01 & $-0.07 \mathrm{~ns}$ & 0.01 & $-0.16^{\star \star}$ & 0.001 \\
\hline Sex (Ref. Female) & $-0.02 \mathrm{~ns}$ & 0.02 & $-0.05 \mathrm{~ns}$ & 0.03 & $-0.11^{\star}$ & 0.11 & $-0.05 \mathrm{~ns}$ & 0.13 & $-0.10 \mathrm{~ns}$ & 0.02 \\
\hline $\begin{array}{l}\text { Level of education (Ref. Low/ } \\
\text { mid) }\end{array}$ & $-0.03 \mathrm{~ns}$ & 0.02 & $0.01 \mathrm{~ns}$ & 0.02 & $-0.05 \mathrm{~ns}$ & 0.08 & $-0.07 \mathrm{~ns}$ & 0.09 & $-0.11^{\star}$ & 0.01 \\
\hline
\end{tabular}


age. The availability of two measures distinct in time of family networks allowed us to create a precise indicator of relationship stability over time, based on the exact number of new alters added over time and of those no longer considered part of the family by respondents. We found compositional changes to have significant effects on all family-based social capital measures. This finding is not in line with some of the predictions of the social Convoy Model (Antonucci et al., 2010, 2014), as it shows that even the most intimate circle of social relationships, namely the family, is subject to a considerable number of changes in old age. Over 20 per cent of the respondents had omitted three or more alters between the two survey waves and over 46 per cent had added either one or two new alters to their family configurations by W2. Given that the name generator used in the questionnaire was limited to five family members and therefore to the family core, these proportions are indeed large and reveal that the extent to which family networks remain stable in their compositions over time in old age is indeed limited. Nevertheless, when reviewing the most cited family terms, ties with immediate family members (one's partner and children) were cited as often or even more often in W2. Our results are thus in agreement with studies that have expected a large variety of patterns of losses but also gains within older adults' relationships (Wenger, 1986; Bowling et al., 1995; van Tilburg, 1998). They demonstrate the importance of compositional dynamics of change for family-based social capital in later years and underscore the importance of considering family networks as dynamic configurations that change over time.

According to previous studies, older adults proactively manage and select their social ties to prioritise engagement with emotionally close contacts (Rook and Charles, 2017). Turnover is thus purposeful and anticipated. Our results show that older adults' family configurations include core family members who tend to remain significant over much of the lifecourse (e.g. children), while many disappear due not only to death but also to conflict or estrangement (Lüscher, 2002; Connidis, 2015; Connidis and Barnett, 2018; Girardin et al., 2018). Indeed, negative interactions in old age can lead to higher levels of emotional distance in relationships because the amount of effort required to maintain them becomes too significant and emotionally taxing (Lang et al., 2013).

New ties can also be activated or reactivated in line with the concepts of family practices and voluntary kin (Braithwaite et al., 2010). The literature on family practices suggests that families are based on sets of activities, which take on a particular meaning at any given point over the lifecourse (Morgan, 1996; Finch, 2007; Morgan, 2011). The focus of this research lies on social actors who creatively constitute their own family worlds, meaning that an individual's understanding of 'my family' is subject to change over time and is deeply rooted in individual biographies (Morgan, 1996). For many people, family relationships extend beyond nuclear families to other households formed through dissolved partnerships and remarriage, co-habitation in the past and in the present, stepfamily relationships, and other various family realities (Finch, 2007; Widmer and Jallinoja, 2008). Our study confirms this understanding of family in later years, as respondents mentioned a large variety of family ties within their most intimate family circles. Many individuals indeed have the capacity to generate new family ties in later years and family life is lived in a diversity of ways that may change over time (Finch, 2007). However, 
for other individuals, limits exist on the availability of close family ties in later life. Being able to cultivate, maintain and engage selectively with a stable set of emotionally close family ties is entwined with experiences early in life that shape attachment styles, coping skills and broader social competencies. Some people undoubtedly reach later adulthood without a stable core of close relationships that can be preserved, and this leads to smaller networks and breaking or losing family ties over time (Morgan, 1996, 2011).

The effect of family-related adverse life events on levels of available family-based social capital was found to be rather marginal. This result suggests that familybased social capital, although it may vary across the lifecourse (Widmer, 2010), is robust to altering life events in old age because family ties are indeed strong with high levels of mutual confidence. This finding can also be explained by processes of compensation arising in larger family networks, e.g. by increasing the prevalence of siblings or other ties in the family network of the respondent (Freund and Baltes, 1998; Baltes and Dickson, 2001; Baltes et al., 2014). This result is also in line with theories of the accumulation of reserves over the lifecourse (Cullati et al., 2018). Evidence points to the fact that family-based social capital is dynamically constructed throughout the lifecourse and that family ties are activated, deactivated or reactivated by individuals according to life circumstances and stressors (Widmer, 2010). Such activation mechanisms apply to family and nonfamily ties. Life transitions and non-normative life events can indeed fundamentally change one's reserve of significant others (Cullati et al., 2018). However, our results show that individuals actively react to life transitions by modifying their family networks, thus modifying their relational reserves over the long term.

The social support literature clearly stresses the need for reciprocal exchanges in maintaining the significance of relationships over time. Reciprocity, over the short or long term, is deemed critical for relationships, and so the activation of relational resources is paramount (Antonucci et al., 1990; Widmer, 2010). Our results are in agreement with this statement, as the levels of reciprocity were found to be higher when new family members were added, which confirms that individuals have a pool of available relatives at their disposal and that reciprocal family ties are reactivated when needed (De Carlo et al., 2014; Cullati et al., 2018). The positive association between the partner's death and levels of reciprocity also confirms this, as it is likely that following the partner's passing, other family relationships were invested in more intensely. Therefore, we argue that considering family as a demographic reserve in future research will help reveal how lifecourse factors and their timing encourage or hinder the acquisition of durable relationships and the family-based social capital that they provide. Such an approach also help us understand the constitution and maintenance of family-based social capital in old age not as a static but rather as a dynamic process of giving and receiving support in which the focal individual plays an active part to maintain the network's benefits (Widmer, 2010).

The high levels of turnover of family network members observed in the sample confirm the importance of adopting a dynamic approach to family in later years. Family and how individuals in later years define it is dynamic and depends on contextual factors and inner motivations. This finding thus draws on the assumption that motivational aspects of agency in networks (along with cognitive awareness of 
network opportunities and actor characteristics) are necessary components of the utility of social connections (Kilduff and Brass, 2010; Westaby et al., 2014). Older adults seek emotionally meaningful ties in their later years (Carstensen, 1992, 1995; Carstensen et al., 2003), but this goal is not always met within the immediate family, which may explain why older adults included in our sample had sought to reactivate dormant ties from kinship reserves (Widmer, 2010; De Carlo et al., 2014).

\section{Limitations}

Our study presents several limitations. The first relates to the fact that the name generator applied for family members was limited to five alters to keep the interview times manageable. Based on evidence stemming from other age groups, it is likely that the inclusion of a larger number of alters would have revealed even more significant changes within the family configurations. Stronger ties, which are cited first in name generators such as that used in this study, are also the most stable and strongest over time, and it is likely that weak ties more than strong ties change and are replaced or added over time (Lubbers et al., 2010). Moreover, the provided information on family members and how they are connected with each other stems from the sole perception of the interviewed individual in line with egocentric network research (Perry, 2018). However, anticipated or perceived support can be of greater importance for older adults than support that was actually received (Krause, 1997).

The aim of this study was to test for effects of family-related life events on family-based social capital in old age. However, from a lifecourse perspective, it is likely that life events occurring in young age and during adulthood also affect levels of support exchanged through family ties in old age (Kaufman and Uhlenberg, 1998). Further research must investigate how and to what extent events occurring at young ages and in mid-adulthood may affect family-based social capital in old age.

Acknowledgements. The authors are grateful to the Swiss National Science Foundation for its financial assistance. The authors also thank participants of the Vivre-Leben-Vivere study and all LIVES project IP3 and LINK Institute members contributing to the realisation of the Vivre-Leben-Vivere study.

Author contributions. JS, EW and MK designed the analyses. JS analysed the data. JS, EW and MK drafted the manuscript. All of the authors contributed to the final version of the article.

Financial support. This work was supported by the Swiss National Centre of Competence in Research project LIVES - Overcoming Vulnerability: Life Course Perspectives, which is financed by the Swiss National Science Foundation (grant number 51NF40-160590).

Conflict of interest. The authors declare no conflicts of interest.

Ethical standards. The present study was conducted in accordance with the Declaration of Helsinki, and the protocol had been approved by the ethics commission of the Faculty of Psychology and Social Sciences of the University of Geneva (project identification codes CE_FPSE_14.10.2010 and CE_FPSE_05.04.2017).

\section{References}

Aartsen MJ, van Tilburg T, Smits CHM and Knipscheer KCPM (2004) A longitudinal study of the impact of physical and cognitive decline on the personal network in old age. Journal of Social and Personal Relationships 21, 249-266. 
Adams RG (1987) Patterns of network change: a longitudinal study of friendships of elderly women. The Gerontologist 27, 222-227.

Antonucci TC (2001) Social relations. An examination of social networks, social support, and sense of control. In Birren JE and Shaie KW (eds). Handbook of the Psychology of Aging. San Diego, CA: Academic Press, pp. 427-453.

Antonucci TC, Fuhrer R and Jackson JS (1990) Social support and reciprocity: a cross-ethnic and crossnational perspective. Journal of Social and Personal Relationships 7, 519-530.

Antonucci TC, Fiori KL, Birditt K and Jackey LMH (2010) Convoys of social relations: integrating lifespan and life-course perspectives. In Lamb ME and Freund AM (eds). The Handbook of Life-span Development. Hoboken, NJ: John Wiley \& Sons, pp. 434-473.

Antonucci TC, Ajrouch KJ and Birditt KS (2014) The Convoy Model: explaining social relations from a multidisciplinary perspective. The Gerontologist 54, 82-92.

Baltes BB and Dickson MW (2001) Using life-span models in industrial-organizational psychology: the theory of selective optimization with compensation. Applied Developmental Science 5, 51-62.

Baltes BB, Wynne K, Sirabian M, Krenn D and Lange A (2014) Future time perspective, regulatory focus, and selection, optimization, and compensation: testing a longitudinal model. Journal of Organizational Behavior 35, 1120-1133.

Bowling A, Grundy E and Farquhar M (1995) Changes in network composition among the very old living in inner London. Journal of Cross-cultural Gerontology 10, 331-347.

Braithwaite DO, Bach BW, Baxter LA, DiVerniero R, Hammonds JR, Hosek AM, Willer EK and Wolf BM (2010) Constructing family: a typology of voluntary kin. Journal of Social and Personal Relationships 27, 388-407.

Broese van Groenou M and Van Tilburg TG (2007) Network analysis. In Birren JE (ed.), Encyclopedia of Gerontology: Age, Ageing, and the Aged. New York, NY: Elsevier, pp. 242-250.

Broese van Groenou M, Hoogendijk EO and van Tilburg TG (2013) Continued and new personal relationships in later life: differential effects of health. Journal of Aging and Health 25, 274-295.

Budgeon S and Roseneil S (2004) Editors' introduction: Beyond the conventional family. Current Sociology 52, 127-134.

Carstensen LL (1992) Social and emotional patterns in adulthood: support for socioemotional selectivity theory. Psychology and Aging 7, 331-338.

Carstensen LL (1995) Evidence for a life-span theory of socioemotional selectivity. Current Directions in Psychological Science 4, 151-156.

Carstensen LL, Fung HH and Charles ST (2003) Socioemotional selectivity theory and the regulation of emotion in the second half of life. Motivation and Emotion 27, 103-123.

Castrén AM (2019) Becoming 'us': marital name, gender, and agentic work in transition to marriage. Journal of Marriage and Family 81, 248-263.

Castrén AM and Ketokivi K (2015) Studying the complex dynamics of family relationships: a figurational approach. Sociological Research Online 20, 108-121.

Castrén AM and Widmer ED (2015) Insiders and outsiders in stepfamilies: adults' and children's views on family boundaries. Current Sociology 63, 35-56.

Coll-Planas L, Gómez G, Bonilla P, Masat T, Puig T and Monteserin R (2017) Promoting social capital to alleviate loneliness and improve health among older people in Spain. Health \& Social Care in the Community 25, 145-157.

Connidis IA (2015) Exploring ambivalence in family ties: progress and prospects. Journal of Marriage and Family 77, 77-95.

Connidis IA and Barnett AE (2018) Family Ties and Aging. Thousand Oaks, CA: Sage.

Cornwell B (2015) Social disadvantage and network turnover. Journals of Gerontology: Psychological Sciences and Social Sciences 70B, 132-142.

Cornwell B and Schafer MH (2016) Social networks in later life. In George LK and Ferraro KF (eds). Handbook of Aging and the Social Sciences, 8th Edn. San Diego, CA: Academic Press, pp. 181-201.

Cornwell B, Laumann EO and Schumm LP (2008) The social connectedness of older adults: a national profile. American Sociological Review 73, 185-203.

Cullati S, Kliegel M and Widmer E (2018) Development of reserves over the life course and onset of vulnerability in later life. Nature Human Behaviour 2, 551-558. 
De Carlo I, Aeby G and Widmer E (2014) La variété des configurations familiales après une recomposition: choix et contraintes. Revue suisse de sociologie 40, 9-27.

Elias N and Scotson JL (1994) The Established and the Outsiders. London: Sage.

EuroQoL Group (1990) EuroQoL: a new facility for the measurement of health-related quality of life. Health Policy 16, 199-208.

Everett M and Borgatti SP (2005) Ego network betweenness. Social Networks 27, 31-38.

Feld SL, Suitor JJ and Hoegh JG (2007) Describing changes in personal networks over time. Field Methods 19, 218-236.

Field D and Minkler M (1988) Continuity and change in social support between young-old and old-old or very-old age. Journal of Gerontology 43, 100-106.

Finch J (2007) Displaying families. Sociology 41, 65-81.

Freund AM and Baltes PB (1998) Selection, optimization, and compensation as strategies of life management: correlations with subjective indicators of successful aging. Psychology and Aging 13, 531-543.

Girardin M and Widmer ED (2015) Lay definitions of family and social capital in later life. Personal Relationships 22, 712-737.

Girardin M, Widmer ED, Connidis IA, Castrén AM, Gouveia R and Masotti B (2018) Ambivalence in later-life family networks: beyond intergenerational dyads. Journal of Marriage and Family 80, 768-784.

Ihle A, Gouveia ÉR, Gouveia BR, van der Linden BWA, Sauter J, Gabriel R, Oris M, Fagot D and Kliegel M (2017) The role of leisure activities in mediating the relationship between physical health and well-being: differential patterns in old and very old age. Gerontology 63, 560-571.

Ihle A, Ghisletta P, Ballhausen N, Fagot D, Vallet F, Baeriswyl M, Sauter J, Oris M, Maurer J and Kliegel $\mathbf{M}$ (2018) The role of cognitive reserve accumulated in midlife for the relation between chronic diseases and cognitive decline in old age: a longitudinal follow-up across six years. Neuropsychologia 121, 37-46.

Kadushin C (2012) Understanding Social Networks: Theories, Concepts, and Findings. New York, NY: Oxford University Press.

Kaufman G and Uhlenberg P (1998) Effects of life course transitions on the quality of relationships between adult children and their parents. Journal of Marriage and Family 60, 924-938.

Kilduff M and Brass DJ (2010) Organizational social network research: core ideas and key debates. Academy of Management Annals 4, 317-357.

Krause N (1997) Anticipated support, received support, and economic stress among older adults. Journals of Gerontology: Psychological Sciences and Social Sciences 52B, 284-293.

Lang FR, Wagner J, Wrzus C and Neyer FJ (2013) Personal effort in social relationships across adulthood. Psychology and Aging 28, 529-539.

Lubbers MJ, Molina JL, Lerner J, Brandes U, Ávila J and McCarty C (2010) Longitudinal analysis of personal networks. The case of Argentinean migrants in Spain. Social Networks 32, 91-104.

Ludwig C, Cavalli S and Oris M (2014) 'Vivre/Leben/Vivere': an interdisciplinary survey addressing progress and inequalities of aging over the past 30 years in Switzerland. Archives of Gerontology and Geriatrics 59, 240-248.

Lüscher K (2002) Intergenerational ambivalence: further steps in theory and research. Journal of Marriage and Family 64, 585-593.

Marsden PV (2002) Egocentric and sociocentric measures of network centrality. Social Networks 24, 407-422.

Moren-Cross JL and Lin N (2006) Social networks and health. In Binstock RH, George LK, Cutler SJ, Hendricks J and Schulz JH (eds), Handbook of Aging and the Social Sciences. Burlington, MA: Academic Press, pp. 111-126.

Morgan DHJ (1996) Family Connections: An Introduction to Family Studies. Cambridge: Polity Press.

Morgan DHJ (2011) Rethinking Family Practices. Basingstoke, UK: Palgrave Macmillan.

Parsons T (1955) Family: Socialization and Interaction Process. New York, NY and London: The Free Press and Collier-Macmillan.

Perry BL (2018) Egocentric Network Analysis: Foundations, Methods, and Models. Cambridge: Cambridge University Press.

Pinquart M and Sörensen S (2000) Influences of socioeconomic status, social network, and competence on subjective well-being in later life: a meta-analysis. Psychology and Aging 15, 187-224.

Portes A (1998) Social capital: its origins and applications in modern sociology. Annual Review of Sociology 24, 1-24. 
Portes A (2000) The two meanings of social capital. Sociological Forum 15, 1-12.

Rook KS and Charles ST (2017) Close social ties and health in later life: strengths and vulnerabilities. American Psychologist 72, 567-577.

Sauter J, Widmer E, Ihle A and Kliegel M (2018) The association of leisure activities in middle adulthood with cognitive performance in old age: social capital mediates cognitive reserve effects. Psychology \& Neuroscience 12, 236-246.

Scott J (2007) Social Network Analysis: A Handbook, 2nd Edn. Los Angeles, CA: Sage.

Sheather S (2009) A Modern Approach to Regression with R. New York, NY: Springer Science \& Business Media.

Shor E, Roelfs DJ and Yogev T (2013) The strength of family ties: a meta-analysis and meta-regression of self-reported social support and mortality. Social Networks 35, 626-638.

Thoits PA (2011) Mechanisms linking social ties and support to physical and mental health. Journal of Health and Social Behavior 52, 145-161.

van Tilburg T (1998) Losing and gaining in old age: changes in personal network size and social support in a four-year longitudinal study. Journals of Gerontology: Psychological Sciences and Social Sciences 53B, 313-323.

van Tilburg T and Groenou MBV (2002) Network and health changes among older Dutch adults. Journal of Social Issues 58, 697-713.

Wenger GC (1986) A longitudinal study of changes and adaptation in the support networks of Welsh elderly over 75. Journal of Cross-cultural Gerontology 1, 277-304.

Westaby JD, Pfaff DL and Redding N (2014) Psychology and social networks: a dynamic network theory perspective. American Psychologist 69, 269-284.

Widmer ED (2006) Who are my family members? Bridging and binding social capital in family configurations. Journal of Social and Personal Relationships 23, 979-998.

Widmer E (2010) Family Configurations: A Structural Approach to Family Diversity. Ashgate, UK: Farnham.

Widmer E and Jallinoja R (2008) Beyond the Nuclear Family: Families in a Configurational Perspective. Bern: Peter Lang.

Widmer ED, Aeby G and Sapin M (2013) Collecting family network data. International Review of Sociology 23, 27-46.

Wrzus C, Hänel M, Wagner J and Neyer FJ (2013) Social network changes and life events across the life span: a meta-analysis. Psychological Bulletin 139, 53-80.

Zartler U (2014) How to deal with moral tales: constructions and strategies of single-parent families. Journal of Marriage and Family 76, 604-619.

Cite this article: Sauter J, Widmer E, Kliegel M (2023). Changes in family composition and their effects on social capital in old age: evidence from a longitudinal study conducted in Switzerland. Ageing \& Society 43, 724-742. https://doi.org/10.1017/S0144686X21000921 